OPEN ACCESS

Edited by:

Alison Buchan,

University of Tennessee, Knoxville,

United States

Reviewed by:

Ludwig Jardillier,

Université Paris-Sud, France

Emilie Lefevre,

Duke University, United States

*Correspondence:

Thijs Frenken

thijs.frenken@gmail.com

Specialty section:

This article was submitted to

Aquatic Microbiology,

a section of the journal

Frontiers in Microbiology

Received: 31 January 2017 Accepted: 22 May 2017

Published: 06 June 2017

Citation:

Frenken T, Wierenga J, Gsell AS,

van Donk E, Rohrlack T and

Van de Waal DB (2017) Changes

in N:P Supply Ratios Affect

the Ecological Stoichiometry of a

Toxic Cyanobacterium and Its Fungal

Parasite. Front. Microbiol. 8:1015.

doi: 10.3389/fmicb.2017.01015

\section{Changes in N:P Supply Ratios Affect the Ecological Stoichiometry of a Toxic Cyanobacterium and Its Fungal Parasite}

\author{
Thijs Frenken ${ }^{1 *}$, Joren Wierenga ${ }^{1}$, Alena S. Gsell ${ }^{1}$, Ellen van Donk ${ }^{1,2}$, Thomas Rohrlack ${ }^{3}$ \\ and Dedmer B. Van de Waal ${ }^{1}$ \\ 'Department of Aquatic Ecology, Netherlands Institute of Ecology (NIOO-KNAW), Wageningen, Netherlands, ${ }^{2}$ Department \\ of Biology, University of Utrecht, Utrecht, Netherlands, ${ }^{3}$ Department of Plant and Environmental Sciences, Norwegian \\ University of Life Sciences, Ås, Norway
}

Human activities have dramatically altered nutrient fluxes from the landscape into receiving waters. As a result, not only the concentration of nutrients in surface waters has increased, but also their elemental ratios have changed. Such shifts in resource supply ratios will alter autotroph stoichiometry, which may in turn have consequences for higher trophic levels, including parasites. Here, we hypothesize that parasite elemental composition will follow changes in the stoichiometry of its host, and that its reproductive success will decrease with host nutrient limitation. We tested this hypothesis by following the response of a host-parasite system to changes in nitrogen $(N)$ and phosphorus $(P)$ supply in a controlled laboratory experiment. To this end, we exposed a fungal parasite (the chytrid Rhizophydium megarrhizum) to its host (the freshwater cyanobacterium Planktothrix rubescens) under control, low N:P and high N:P conditions. Host N:P followed treatment conditions, with a decreased $N: P$ ratio under low $N: P$ supply, and an increased N:P ratio under high N:P supply, as compared to the control. Shifts in host $\mathrm{N}: P$ stoichiometry were reflected in the parasite stoichiometry. Furthermore, at low N:P supply, host intracellular microcystin concentration was lowered as compared to high $\mathrm{N}: \mathrm{P}$ supply. In contrast to our hypothesis, zoospore production decreased at low N:P and increased at high N:P ratio as compared to the control. These findings suggest that fungal parasites have a relatively high $\mathrm{N}$, but low $\mathrm{P}$ requirement. Furthermore, zoospore elemental content, and thereby presumably their size, decreased at high N:P ratios. From these results we hypothesize that fungal parasites may exhibit a trade-off between zoospore size and production. Since zooplankton can graze on chytrid zoospores, changes in parasite production, stoichiometry and cell size may have implications for aquatic food web dynamics.

Keywords: nutrients, harmful algal blooms, plankton, Chytridiomycota, disease, pathogen, microcystin

\section{INTRODUCTION}

Human activities have substantially increased the flux of nutrients from land into receiving waters (Smith, 2003). This nutrient enrichment enhances aquatic primary production, and may lead to dramatic changes in the composition and structure of aquatic food webs (Schindler and Fee, 1974; Smith et al., 2006). Specifically, an increased nutrient supply might promote development 
of harmful cyanobacterial blooms (Paerl et al., 2001, 2011; Smith and Schindler, 2009). Although nutrient loading has increased, primary production in aquatic ecosystems is often still limited by nitrogen (N) and/or phosphorus (P) (Elser et al., 2007; Bracken et al., 2014). This may be a result of an imbalanced nutrient supply (Carpenter et al., 1996; Sterner et al., 2007), as well as an increased nutrient demand associated to high phytoplankton densities (Carpenter et al., 1996). Nutrient limitation will alter the elemental composition of phytoplankton, and may specifically increase carbon:nutrient ratios (Sterner and Elser, 2002). As a consequence, nutritional quality of the phytoplankton decreases, thereby possibly constraining higher trophic levels (Sterner and Elser, 2002; Hessen et al., 2013). This may particularly apply to parasites that solely depend on their host as a food source (Smith, 2007).

Fungal parasites are very common pathogens infecting phytoplankton (Gerphagnon et al., 2015), which represent an important but yet overlooked ecological driving force in aquatic food web dynamics (Sime-Ngando, 2012). These parasites, belonging to the phylum Chytridiomycota and often referred to as chytrids, are host specific zoosporic fungi that can parasitize on phytoplankton and completely rely on their host to obtain energy and nutrients leading to death of the host (Sparrow, 1960, 1968; Barr, 2001). Thereby, they play an important role in natural aquatic ecosystems, in which chytrids can significantly change phytoplankton abundance and seasonal succession (Reynolds, 1973; Van Donk, 1984, 1989). Additionally, the free swimming stage of the chytrids (i.e., zoospores) may provide higher trophic levels with an alternative food source during blooms of large inedible diatoms (Kagami et al., 2007; Frenken et al., 2016) or cyanobacteria (Agha et al., 2016). Earlier work indicates that zoospores might find their host by chemotaxis (Muehlstein et al., 1988), and penetrate host cells using a rhizoidal system through which nourishment is conveyed to the zoospore (Van Donk and Ringelberg, 1983). After infection, the spore forms a sessile stage (i.e., sporangium) in which new zoospores (up to 60) are produced (Canter and Lund, 1951; Sparrow, 1960).

Chytrid zoospores generally contain a relatively high amount of nucleic acids that are particularly rich in $\mathrm{P}$, but also contain substantial amounts of lipids, including fatty acids and sterols, which are rich in carbon (Barr and Hadland-Hartmann, 1978; Beakes et al., 1988, 1993; Elser et al., 1996; Kagami et al., 2007). Chytrids thus seem to have high P demands, as has been indicated by their low C:P as compared to their host (Kagami et al., 2007). As a consequence, limitation by $\mathrm{P}$ may affect a chytrid more than its host. Chytrid infections were indeed shown to be affected by host $\mathrm{P}$ limitation. More specifically, chytrid growth rate and the number of zoospores per sporangium decreased, and, as a function of lower host growth rate, zoospore loss as well as searching time increased, as compared to non-limited conditions (Bruning, 1991). If, however, P limitation impedes algal growth to a greater extent than that of the chytrid, epidemics may still occur (Bruning and Ringelberg, 1987; Bruning, 1991).

Nutrient limitation not only alters growth and reproduction of the parasite, it may also affect host defense. Freshwater cyanobacteria produce a wide range of oligopeptides including toxic microcystins (MC) (Welker and Von Döhren, 2006), which have been associated to chytrid defense (Rohrlack et al., 2013). These oligopeptides are $\mathrm{N}$ rich compounds, and their synthesis is typically constrained under $\mathrm{N}$ limitation (Van de Waal et al., 2010, 2014). Thus, during low N:P conditions, host defense may be reduced and thereby facilitate chytrid infections. In contrast, cellular $\mathrm{N}$ may accumulate under high $\mathrm{N}: \mathrm{P}$ conditions and thereby enhance host defense. Limitation by $\mathrm{N}$ and $\mathrm{P}$ may thus have contrasting effects on chytrid infections of cyanobacteria. We hypothesized that parasite elemental composition will follow changes in the stoichiometry of its host, and that its reproductive success will decrease with host nutrient limitation. To test this hypothesis, we exposed the cyanobacterium Planktothrix rubescens to its chytrid Rhizophydium megarrhizum under control, low $\mathrm{N}$ and low $\mathrm{P}$ conditions, leading to a range of host $\mathrm{N}: \mathrm{P}$ ratios. We predict that infections will decrease with increasing host $\mathrm{N}: \mathrm{P}$, as the availability of $\mathrm{P}$ for chytrid nutrition will decrease and the host defense by oligopeptides will increase.

\section{MATERIALS AND METHODS}

\section{Description of Test Organisms}

In this study the filamentous cyanobacterial host $P$. rubescens NIVA-CYA97/1 was used in combination with one of its parasites, the chytrid Chy-Lys2009 (photo provided in the Supplementary Material). This chytrid possesses identical morphological characteristics and infection patterns in agreement with R. megarrhizum described earlier by Canter and Lund (1951). More information on host specificity and virulence of the chytrid can be found in Sønstebø and Rohrlack (2011) and Rohrlack et al. (2013). All cultures used in this study were monoclonal and non-axenic.

\section{Culture Maintenance}

The Planktothrix and the chytrid Chy-Lys2009 cultures were grown in a temperature and light controlled incubator (Snijders Labs, Tilburg, The Netherlands) at $5 \mu \mathrm{mol}$ photons $\mathrm{m}^{-2} \mathrm{~s}^{-1}$ in a 14:10 light:dark cycle, at 24 and $16^{\circ} \mathrm{C}$, respectively. The applied low light levels resemble the conditions where the tested Planktothrix species was isolated, i.e., in the vicinity of the thermocline. All cultures were maintained in exponential growth in batch using $100 \mathrm{~mL}$ Erlenmeyer flasks with $50 \mathrm{~mL}$ suspension. Every other week, Planktothrix cultures were diluted using WCmedium (Guillard and Lorenzen, 1972) and chytrid cultures were diluted using host culture and WC-medium to $1 / 10(\mathrm{v} / \mathrm{v})$. Additionally, Erlenmeyer flasks were shaken every other day to prevent aggregation. The chytrid cultures were visually inspected for infection patterns and contaminations at least once a week.

\section{Description of the Experiment Culture Acclimatization and Inoculation}

Prior to the experiment, Planktothrix was grown at $16^{\circ} \mathrm{C}$ on $\mathrm{WC}$ medium at three distinct $\mathrm{N}: \mathrm{P}$ supply ratios by modifying standard $\mathrm{NO}_{3}{ }^{-}$and $\mathrm{PO}_{4}{ }^{3-}$ concentrations of 1000 and $50 \mu \mathrm{mol} \mathrm{L}{ }^{-1}$ $(\mathrm{N}: \mathrm{P}=20)$ as control, to 200 and $50 \mu \mathrm{mol} \mathrm{L}{ }^{-1}(\mathrm{~N}: \mathrm{P}=4)$ as the low N:P treatment, and 1000 and $10 \mu \mathrm{mol} \mathrm{L}^{-1}(\mathrm{~N}: \mathrm{P}=100)$ as the high $\mathrm{N}: \mathrm{P}$ treatment. Cultures were acclimatized for about 
18 generations to the distinct nutrient conditions by three consecutive transfers at late exponential phase. During each transfer, i.e., after each 7 days period, cultures were diluted back to half of maximum biovolume reached in order to maintain nutrient limited conditions. After acclimatization, Planktothrix was first grown without chytrids (unexposed treatment, 4 replicates per nutrient treatment, 12 experimental units) to late stationary phase to obtain uninfected host growth rates, stoichiometry and toxin composition. Subsequently, the host cultures were then pooled by nutrient treatment and used to inoculate the chytrid exposed treatments (4 replicates per nutrient treatment, 12 experimental units). At the start of the chytrid exposed treatment, Planktothrix cultures were inoculated together with a zoospore suspension that was obtained from a highly infected Planktothrix culture (with 58\% Chy-Lys2009 infected filaments) by sieving gently over a $30 \mu \mathrm{m}$ and a subsequent $5 \mu \mathrm{m}$ nylon mesh to remove host cells, while collecting zoospores that have a typical size range of $2.5-3.5 \mu \mathrm{m}$ (Sparrow, 1960). This zoospore suspension was washed with $\mathrm{N}$ and $\mathrm{P}$ free WC-medium and concentrated on a $1.2 \mu \mathrm{m}$ cellulose acetate membrane filter (Whatman, Maidstone, United Kingdom), and used to inoculate to a final density of 18 zoospores $\mathrm{mL}^{-1}$. The chytrid exposed cultures were grown for 7 days to obtain host and parasite growth rates, host and parasite stoichiometry, parasite zoospore production and toxin composition of parasite exposed host. Each treatment was performed in $500 \mathrm{~mL}$ Erlenmeyer flasks with $300 \mathrm{~mL}$ of culture.

\section{Host and Parasite Quantification}

During the experiment, cultures were sampled daily to determine biovolume using a CASY Cell Counter (Schärfe System GmbH, Reutlingen, Germany). Next, at least $5 \mathrm{~mL}$ of culture suspension was fixed with alkaline Lugol's iodine solution to a final concentration of $1.2 \%(\mathrm{v} / \mathrm{v})$ and stored in the dark at room temperature. Prevalence of infected filaments was counted in duplicate (technical replicate) for each biological replicate within 2 weeks after the experiment by inspecting at least 50 filaments. Additionally, during the infection treatment, the number of free swimming zoospores was counted daily in duplicate, also for each biological replicate, in at least 15 fields of view (FOV) in fresh cultures. All microscopic counting was performed using a magnification of $200 \times$ on an inverted microscope (DMI 4000B, Leica Microsystems CMS GmbH, Mannheim, Germany). Cultures were harvested at the early stationary phase for the analyses of dissolved inorganic nutrients, elemental composition of the host and parasite, and the MC contents and composition of the host.

\section{Elemental Analyses}

Particulate organic carbon (C), $\mathrm{N}$ and $\mathrm{P}$ were determined in duplicate by collecting 5-15 $\mathrm{mL}$ of seston on a prewashed GF/F filter (Whatman, Maidstone, United Kingdom) applying gentle filtration $(<1-2 \mathrm{psi})$. Filters were dried overnight at $60^{\circ} \mathrm{C}$, and stored in a desiccator in the dark. For $\mathrm{C}$ and $\mathrm{N}$ analyses, a subsample $(22 \%)$ of every filter was taken by a hole puncher, folded into a tin cup and analyzed on a FLASH 2000 organic elemental analyzer (Brechbueler Incorporated, Interscience B.V., Breda, The Netherlands). Particulate organic P was analyzed (Eaton, 2005) by first combusting the remainder of the filter (78\%) for $30 \mathrm{~min}$ at $550^{\circ} \mathrm{C}$ in Pyrex glass tubes, followed by a digestion step with $2.5 \mathrm{~mL}$ persulfate $(2.5 \%)$ for $30 \mathrm{~min}$ at $120^{\circ} \mathrm{C}$. This digested solution was measured for $\mathrm{PO}_{4}{ }^{3-}$ on the QuAAtro39 AutoAnalyzer (SEAL Analytical Ltd, Southampton, United Kingdom) following Armstrong et al. (1967). During the infection treatment, particulate organic $\mathrm{C}, \mathrm{N}$ and $\mathrm{P}$ were determined for the seston fraction as well as for the zoospores. For this purpose, 90-160 $\mathrm{mL}$ infected culture suspension was gently filtered twice over a $30 \mu \mathrm{m}$ nylon mesh filter to remove the larger cyanobacterial filaments. Subsequently, the smaller filaments were removed by an additional filtration over a $5 \mu \mathrm{m}$ nylon mesh, and zoospores in the filtrate were collected on a prewashed GF/F filter (Whatman GF/F, Maidstone, United Kingdom). Organic C, N and P on the filters were analyzed as described above.

\section{Microcystin Analyses Extractions}

Samples for MC analyses were collected in duplicate by filtering 5-15 mL of culture over a GF/C filter (Whatman, Maidstone, United Kingdom) applying low pressure after which the filters were stored at $-20^{\circ} \mathrm{C}$. Filters were lyophilized overnight before performing three rounds of extractions at $60^{\circ} \mathrm{C}$ using $2.5 \mathrm{~mL} 75 \%$ methanol-25\% Millipore water (v/v) in $8 \mathrm{~mL}$ Pyrex glass tubes. After drying the samples with $\mathrm{N}_{2}$, extracts were reconstituted in $900 \mu \mathrm{l}$ methanol, filtered and centrifuged (Corning®) Costar $\odot$ Spin-X( polypropylene centrifuge tube filters with a $0.22 \mu \mathrm{m}$ cellulose-acetate filter (Corning Inc., Corning, NY, United States) for $5 \mathrm{~min}$ at 16,000 $\times g$ (Sigma 1-15P, Sigma Laborzentrifugen $\mathrm{GmbH}$, Osterode am Harz, Germany). Filtrates were transferred to amber glass vials and analyzed by LC-MS/MS.

\section{Analyses}

Samples were analyzed for eight MC variants (dm-7-MC-RR, MC-RR, MC-YR, dm-7-MC-LR, MC-LR, MC-LY, MC-LW, and MC-LF). Calibration standards were obtained from the National Research Council (Ottawa, Canada) for dm-7-MC-LR, and from Enzo Life Sciences Inc. (Farmingdale, NY, United States) for the other variants. Measurements were performed on an Agilent 1260 LC and an Agilent 6460A QQQ (Agilent Technologies, Santa Clara, CA, United States). The compounds were separated on an Agilent Zorbax Eclipse XDB-C18 $4.6 \mathrm{~mm} \times 150 \mathrm{~mm}$, $5 \mu \mathrm{m}$ column using Millipore water with $0.1 \%$ formic acid ( $v / v$, eluent A) and acetonitrile with $0.1 \%$ formic acid ( $v / v$, eluent B). The elution program was set at 0-2 min 30\% B, 6-12 min $90 \%$ B, with a linear increase of $\mathrm{B}$ between 2 and $6 \mathrm{~min}$ and a 5 min post run at $30 \%$ B. Sample injection volume was set at $10 \mu \mathrm{L}$, with a flow of $0.5 \mathrm{~mL} \mathrm{~min} \mathrm{~m}^{-1}$ at a column temperature of $40^{\circ} \mathrm{C}$. The LC-MS/MS was operated in positive mode with an ESI source, nitrogen was used as a drying, sheath and collision gas. For each compound, two transitions were monitored in MRM mode: $m / z$ 491.3 to $\mathrm{m} / z 135.1$ and $\mathrm{m} / z 981.5$ to $\mathrm{m} / z 135.2$ (dm-7-MC-LR, ratio between product ions $17 \%), \mathrm{m} / z 498.3$ to $\mathrm{m} / z 135.1$ and $\mathrm{m} / z 995.6$ to $\mathrm{m} / z 135.1$ (MC-LR, ratio between product ions 
$16 \%)$. This protocol is based on the protocol earlier described by Faassen and Lürling (2013).

\section{Data Analyses}

Host population growth and zoospore production rates were calculated according to $\mu=\ln \left(B_{\mathrm{n}+\mathrm{t}} / B_{\mathrm{n}}\right) / t$. In which $\mu$ is the maximum specific growth rate, $B_{\mathrm{n}}$ is the initial population density of non-infected or infected host (biovolume), or zoospores (counts), $B_{\mathrm{n}+\mathrm{t}}$ is the final population density of these variables over time $t$ in the exponential growth phase. Infected biomass was calculated by multiplying the proportion of infected filaments with biovolume. Zoospore production efficiency was calculated as the number of zoospores produced per infected host biovolume.

Host maximum specific growth rate, zoospore production rate, seston stoichiometry of the host and parasite and MC content of the host were tested for normality and equal variance using the Shapiro-Wilk and Brown-Forsythe tests, respectively. Data were transformed, log or reciprocal, if this improved normality. Host growth rates, zoospore production rate, seston and zoospore stoichiometry and host MC content were analyzed to test for effects of nutrient supply by performing a oneway ANOVA. Pairwise comparisons were conducted using the Holm-Sidak test (Sidak, 1967). The strength and direction of associations between variables were assessed by Pearson product-moment correlations. All analyses were performed using SigmaPlot version 13 (Systat Software Inc., London, United Kingdom). Detailed output of the different statistical tests can be found in the Supplementary Material.

\section{RESULTS}

\section{Host Growth and Biovolume Build-Up}

In the absence of the parasite, Planktothrix population growth rates were comparable in all treatments (Table 1), with replicates ranging between 0.30 and $0.59 \mathrm{~d}^{-1}$. In the presence of the parasite, nutrient supply also had no clear effect on net population growth rate of the total biovolume (Table 1). After 4 days of infection, infected host biomass increased at the expense of susceptible host biomass (Figure 1). The total Planktothrix biomass build-up after 4-7 days was lower in the chytrid exposed cultures than in the unexposed cultures. The rate at which the infected biomass increased was highest under a high N:P supply, while it did not differ between the control and low N:P treatment (Table 1).

\section{Elemental Composition}

Host N:P ratios followed N:P supply $(r=0.99, P<0.001$; Table 2), and were lowest with $7.8 \pm 0.1$ (mean \pm SE) under low N:P conditions, intermediate with $11.4 \pm 0.4$ in the control, and highest with $46.2 \pm 2.7$ under high $\mathrm{N}$ :P conditions (Figure 2A). This was also largely resembled in the overall N:P ratios of the cultures when the parasite was present (i.e., infected host + chytrids). The $\mathrm{N}: \mathrm{P}$ ratio in the high $\mathrm{N}: \mathrm{P}$ treatments was also highest with $44.2 \pm 1.7$, while the low N:P treatment and the control were not statistically different with an N:P ratio of $8.6 \pm 0.22$ and $10.3 \pm 0.14$, respectively. Similarly, N:P ratios of the chytrid zoospores increased with host $\mathrm{N}: \mathrm{P}$ ratios $(r=0.96, P<0.001)$. Specifically, chytrid N:P ratios increased from $12.6 \pm 0.4$ in the control to $25.9 \pm 1.0$ under high $\mathrm{N}: \mathrm{P}$, while remained largely unaltered in the low $\mathrm{N}: \mathrm{P}$ treatment as compared to the control (Figure 2B and Table 3).

The observed shifts in host N:P ratios were mainly caused by changes in $\mathrm{P}$ contents $(r=-0.97, P<0.001)$, which decreased from $107.8 \pm 2.5 \mathrm{pmol} \mathrm{mm}^{-3}$ at low $\mathrm{N}: \mathrm{P}$ conditions down to $82.7 \pm 4.3 \mathrm{pmol} \mathrm{mm}^{-3}$ in the control and $17.2 \pm 1.0 \mathrm{pmol} \mathrm{mm}^{-3}$ under high $\mathrm{N}: \mathrm{P}$ conditions, while $\mathrm{C}$ and $\mathrm{N}$ contents remained largely unaltered across all treatments (Figure 2C and Table 2). Zoospore $\mathrm{C}, \mathrm{N}$ as well as $\mathrm{P}$ contents decreased with increasing host $\mathrm{N}: \mathrm{P}(r=-0.77, P=0.003, r=-0.77, P=0.003$ and $r=-0.84, P<0.001$, respectively), with highest values under low $\mathrm{N}: \mathrm{P}$ conditions, intermediate values in the control, and lowest values under high N:P conditions (Figure 2D and Table 3). The observed difference in N:P stoichiometry between high N:P conditions and the other nutrient supply treatments resulted from a stronger decline in $\mathrm{P}$ contents relative to $\mathrm{N}$.

\section{Parasite Prevalence and Production}

Prevalence of infection on the last day of the experiment ranged between $30 \pm 1.4 \%$ (mean $\pm \mathrm{SE}$ ) in the control up to $48 \pm 2.1 \%$ and $56 \pm 3.6 \%$ in high N:P and low N:P treatments, respectively (Figure 3A). Growth rates of the infection were highest in the high N:P cultures and lowest, although not significantly, in the low N:P cultures (Table 1). Comparably, zoospore concentrations, zoospore production rate and the amount of zoospores produced per unit of infected host biomass, i.e., the zoospore production efficiency, were all highest in the high $\mathrm{N}: \mathrm{P}$ cultures and lowest in low N:P cultures (Figures 3B, 4A,B and Table 4). Zoospore production rate and efficiency increased with host $\mathrm{N}: \mathrm{P}$ ratio $(r=0.61, P=0.035$, and $r=0.85, P<0.001$, respectively), while production efficiency furthermore decreased with zoospore $\mathrm{C}$ contents ( $r=-0.87, P<0.001$; Figure 4C).

\section{Microcystin}

Four MC variants were detected, including dm-7-MC-RR, MCYR, dm-7-MC-LR, and MC-LR. On average, dm-7-MC-RR was the dominant $\mathrm{MC}$ variant present, representing $56.6 \pm 0.5 \%$ (mean $\pm \mathrm{SE}$ ) of the total amount of MC. The total cellular

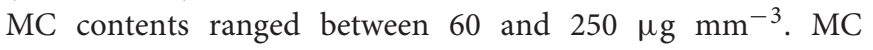
concentrations were highest in the high $\mathrm{N}: \mathrm{P}$, lowest in the low N:P, and intermediate in the control treatment (Figure 5). Furthermore, in the chytrid exposed cultures, the total amount of intracellular MC seemed to be lower.

\section{DISCUSSION}

Although the different nutrient supply ratios had only minor effects on Planktothrix growth rates after acclimatization (Table 1), there were clear changes in the elemental composition of the cyanobacteria (Figure 2A). This indicates that nutrient depletion did affect host physiology, but not growth, at the time of sampling. Apparently, Planktothrix is able to maintain similar maximum growth rates as compared to the control at 
TABLE 1 | Planktothrix maximum net population growth rates $\left(\mathrm{d}^{-1}\right)$ of the different biomass fractions in the unexposed and chytrid exposed cultures.

\begin{tabular}{|c|c|c|c|c|}
\hline \multirow[b]{2}{*}{ Treatment } & \multirow{2}{*}{$\begin{array}{c}\text { Unexposed } \\
\text { Total }\end{array}$} & \multicolumn{3}{|c|}{ Exposed } \\
\hline & & Total & Susceptible & Infected \\
\hline Control & $0.40 \pm 0.04^{\mathrm{a}}$ & $0.11 \pm 0.04^{\mathrm{a}}$ & $0.10 \pm 0.03^{b}$ & $0.92 \pm 0.09^{a}$ \\
\hline High N:P & $0.40 \pm 0.06^{a}$ & $0.11 \pm 0.03^{a}$ & $0.10 \pm 0.03^{b}$ & $1.34 \pm 0.09^{b}$ \\
\hline
\end{tabular}

Superscript letters denote significant differences between nutrient treatments based on One-way ANOVA and post hoc comparison of the means ( $\alpha<0.05)$.

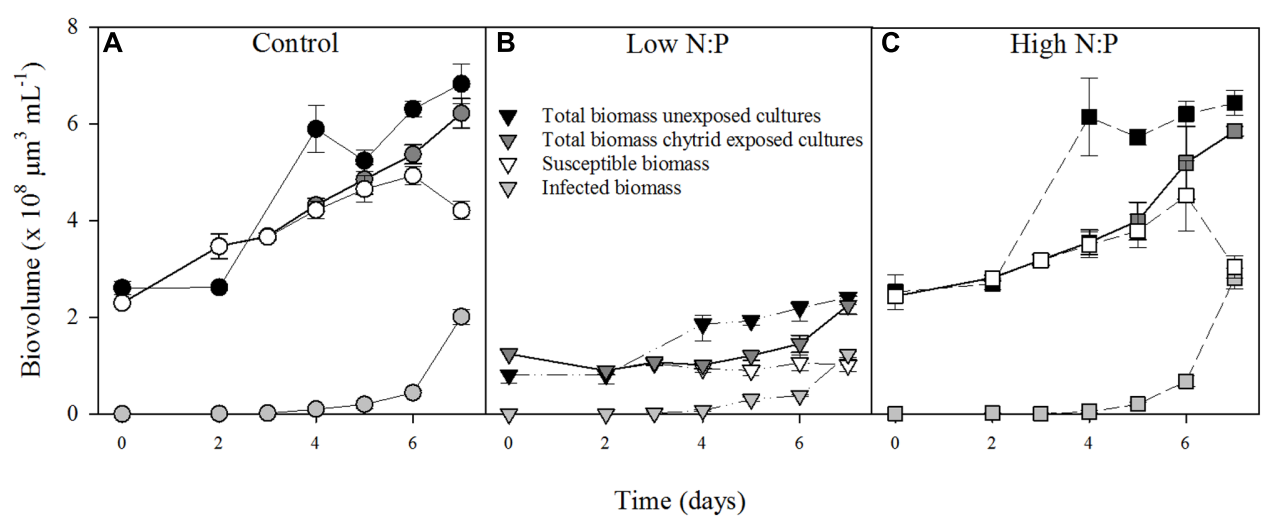

FIGURE 1 | Biovolumes of Planktothrix in the in the cultures with and without parasite exposure in the control (A), low N:P (B) and high N:P (C) treatments. Symbols represent mean \pm standard error $(n=4)$.

TABLE 2 | Host nutrient content and stoichiometry (mean \pm SE) in unexposed cultures.

\begin{tabular}{|c|c|c|c|c|c|c|}
\hline Treatment & \multicolumn{3}{|c|}{ Nutrient content $\left(10^{-6} \mu \mathrm{mol} \mathrm{mm} \mathrm{mm}^{-3}\right)$} & \multicolumn{3}{|c|}{ Stoichiometry (molar) } \\
\hline Control & $4098 \pm 120^{b}$ & $935 \pm 26^{a}$ & $83 \pm 4^{b}$ & $49.9 \pm 1.9^{a}$ & $4.4 \pm 0.0^{b}$ & $11.4 \pm 0.4^{b}$ \\
\hline High N:P & $3705 \pm 242^{b}$ & $791 \pm 48^{b}$ & $17 \pm 1^{\mathrm{c}}$ & $216.4 \pm 11.7^{\mathrm{b}}$ & $4.7 \pm 0.1^{b}$ & $46.2 \pm 2.7^{\circ}$ \\
\hline
\end{tabular}

Superscript letters denote significant differences between nutrient treatments based on One-way ANOVA and post hoc comparison of the means ( $\alpha<0.05)$.

both a high and low N:P supply ratio (Table 1 ). The reduced host N:P under low N:P supply and increased host N:P under high N:P supply (Figure 2A) indicates nutrient limitation at the end of the exponential phase and/or early stationary phase. Moreover, population densities in the low N:P treatment at the end of the experiment were lower as compared to the control and high N:P treatment (Figure 1B). These lower population densities are mainly caused by a low $\mathrm{N}$ availability in the low $\mathrm{N}: \mathrm{P}$ treatment, but may also result from the lower Planktothrix population densities at the start of the experiment. Differences in host population density may affect light availability in the cultures. A lowered population density, as observed in the low $\mathrm{N}: \mathrm{P}$ treatment, may have resulted in an increased light availability due to reduced self-shading. Earlier studies have indicated that zoospores may find their host using chemical cues that are related to photosynthetic activity, since zoospores are generally attracted to carbohydrates, polysaccharides, proteins and amino acids (Muehlstein et al., 1988; Donaldson and Deacon, 1993; Moss et al., 2008). Some studies, however, also reported attachment of zoospores to new hosts during dark conditions (Barr and Hickman, 1967). Indirectly, the relative higher light availability in the low N:P treatment may thus have favored parasite attraction. Moreover, with a comparable amount of zoospores added at the start of the experiment, the zoospore-to-host ratio was also higher in the $\mathrm{N}$ limited treatment, which may favor infection rates. Yet, both the zoospore production rate and production efficiency were lower in the low $\mathrm{N}: \mathrm{P}$ treatment, and did not lead to a different infection rate as compared to the control (Table 1). This suggests that higher relative light availabilities as well as higher initial zoospore-to-host ratios did not stimulate, and possibly even impeded the infection dynamics in our low $\mathrm{N}: \mathrm{P}$ treatment.

In response to an increased $\mathrm{N}: \mathrm{P}$ supply in the medium, host $\mathrm{N}: \mathrm{P}$ increased as well. This resulted in a consecutive increase in the N:P of the zoospores (Figure 2B). Our results thus show that stoichiometry of a host can cascade to their parasites. In the host, changes in stoichiometry seem to be driven mainly by a change in $\mathrm{P}$ content, as host $\mathrm{C}$ and $\mathrm{N}$ remain constant with changing $\mathrm{N}: \mathrm{P}$ supply (Figure $2 \mathrm{C}$ ). In the parasite, changes 

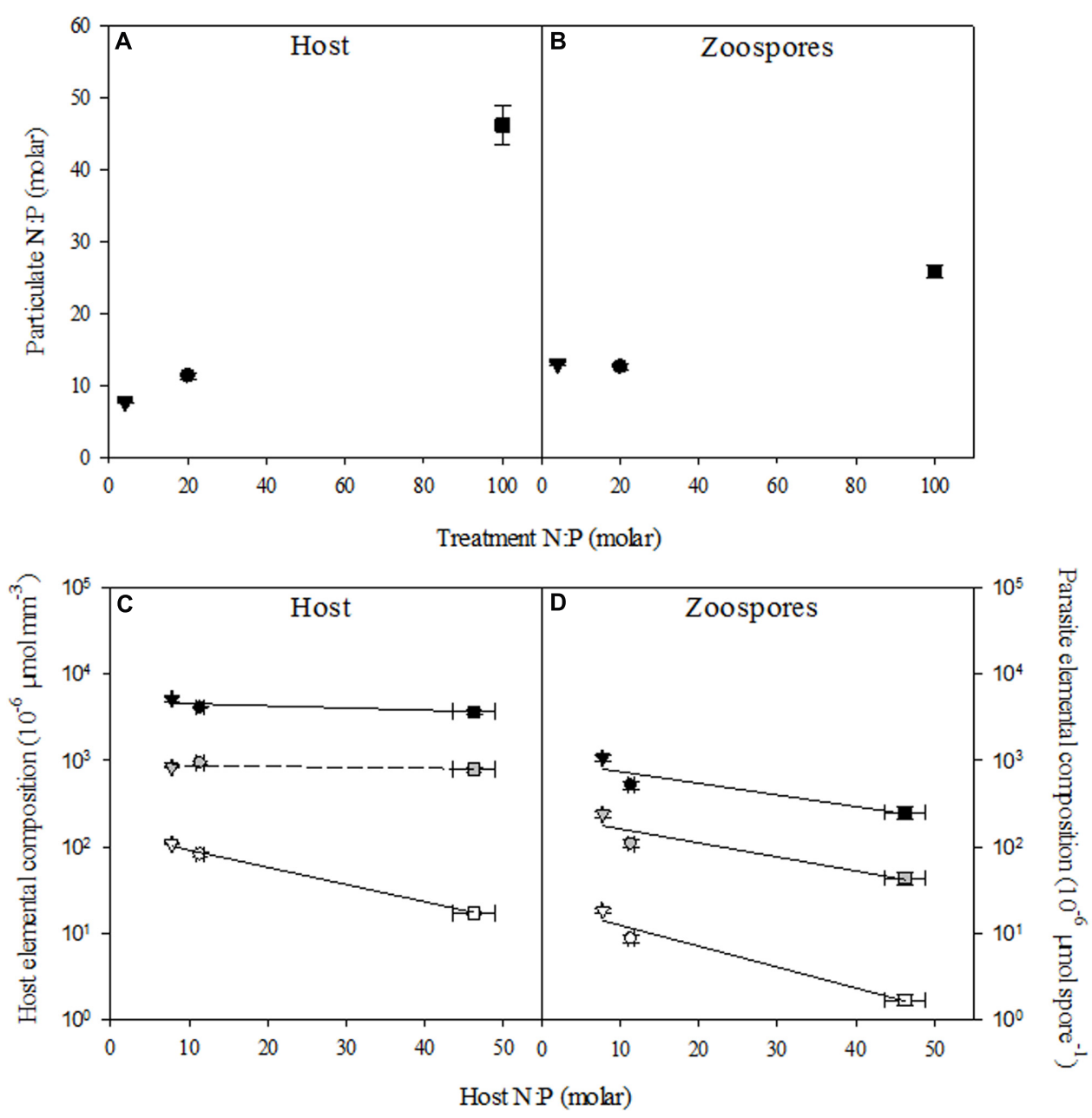

FIGURE 2 | N:P ratios of uninfected host (A) and zoospores (B), and elemental content of the host (C) and zoospores (D) in the control (circle), low N:P (triangle) and high N:P (square) treatments. Symbols represent mean \pm standard error $(n=4)$. In $(\mathbf{C}, \mathbf{D})$ black, gray, and white symbols indicate carbon, nitrogen and phosphorus content, respectively. Solid lines indicate significant correlations $(P<0.05)$.

TABLE 3 | Zoospore nutrient content and stoichiometry (mean \pm SE).

\begin{tabular}{|c|c|c|c|c|c|c|}
\hline \multirow[b]{2}{*}{ Treatment } & \multicolumn{3}{|c|}{ Nutrient content ( $\times 10^{-4} \mu \mathrm{mol}$ per spore) } & \multicolumn{3}{|c|}{ Stoichiometry (molar) } \\
\hline & C & $\mathbf{N}$ & $\mathbf{P}$ & C:P & $\mathrm{C}: \mathrm{N}$ & N:P \\
\hline Low N:P & $10.71 \pm 0.77^{a}$ & $2.41 \pm 0.18^{a}$ & $0.19 \pm 0.01^{\mathrm{a}}$ & $57.8 \pm 0.7^{a}$ & $4.4 \pm 0.0^{\mathrm{a}}$ & $13.0 \pm 0.2^{a}$ \\
\hline Control & $5.27 \pm 0.55^{b}$ & $1.11 \pm 0.11^{b}$ & $0.09 \pm 0.01^{b}$ & $59.9 \pm 1.7^{\mathrm{a}}$ & $4.7 \pm 0.0^{b}$ & $12.6 \pm 0.4^{a}$ \\
\hline High N:P & $2.63 \pm 0.49 c$ & $0.45 \pm 0.08^{c}$ & $0.02 \pm 0.00^{c}$ & $149.9 \pm 6.5^{b}$ & $5.8 \pm 0.1^{c}$ & $25.9 \pm 1.0^{b}$ \\
\hline
\end{tabular}

Superscript letters denote significant differences between nutrient treatments based on One-way ANOVA and post hoc comparison of the means ( $\alpha<0.05)$.

in zoospore stoichiometry are also mainly driven by $\mathrm{P}$ content, but $\mathrm{C}$ and $\mathrm{N}$ contents decrease as well. Yet, $\mathrm{P}$ content decreases faster, suggesting a higher flexibility of the chytrid with respect to $\mathrm{P}$ (Figure 2D). These findings indicate that chytrid parasites can be stoichiometrically flexible, while maintaining their ability to infect along an $\mathrm{N}: \mathrm{P}$ supply gradient. $\mathrm{N}: \mathrm{P}$ and $\mathrm{C}: \mathrm{P}$ ratios of the chytrid used in this experiment are relatively high as compared to two other studies using different chytrid species (Kagami et al., 2007, 2017), but fall well within the range of aquatic fungi reported before (Danger and Chauvet, 2013; Danger et al., 2015). These data furthermore suggest that fungal elemental homeostasis is indeed limited (Persson et al., 2010; Danger et al., 2015). Zoospore N:P ratios largely resembled that of the host under control conditions, but were different from the host in the low and high N:P treatment. We could not separate zoospores from the heterotrophic bacteria, and our results may therefore have been confounded by shifts in bacterial numbers. To prevent high bacterial numbers fueled by the lyses of 

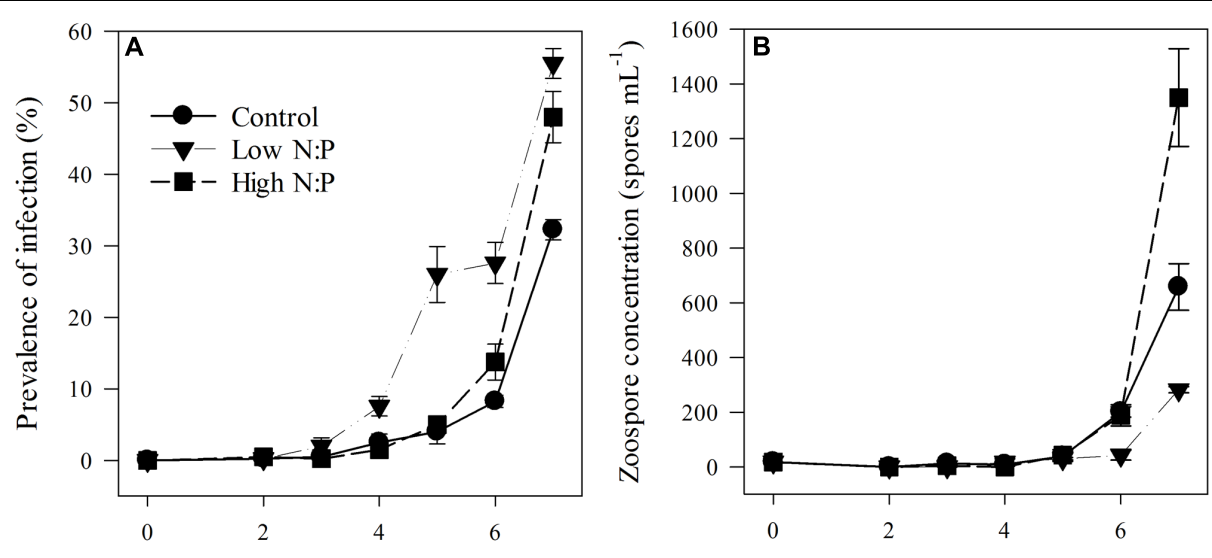

Time (days)

FIGURE 3 | Prevalence of infection (A) and zoospore concentration (B) in the control, low N:P and high N:P treatments. Symbols represent mean \pm standard error $(n=4)$.

Planktothrix, we ran the experiments over a relatively short time period. Consequently, the overall biomass of bacteria and thereby their contribution to the elemental composition at the time of sampling is likely to be small.

Increasing $\mathrm{N}: \mathrm{P}$ supply ratios resulted in an increased zoospore production rate and production efficiency (Figures 4A,B). These results are in contrast to earlier findings of an experiment that showed that under P-limitation (and presumably high $\mathrm{N}: \mathrm{P})$ zoospore production decreased (Bruning, 1991). It might be possible that the chytrid species ( $R$. planktonicum Canter emend.) used in the experiment by Bruning (1991) has higher P-requirements, and therefore suffered more from P-limitation. Or, because the chytrid in our experiment can potentially infect and exploit multiple adjacent cells within one cyanobacterial filament (Canter and Lund, 1951), it might be less vulnerable to nutrient limitation. In other words, the chytrid might continue infecting adjacent cells until it has consumed sufficient nutrients to complete an infection cycle. However, this is only profitable if the energetic costs of growing rhizoids and producing degrading enzymes to invade host cells balance the gains with respect to resource acquisition.

Under low N:P conditions, the parasite zoospores were fewer but contained more $\mathrm{C}$, as well as $\mathrm{N}$ and $\mathrm{P}$ as compared to the control (Figure 2D). Although we did not assess zoospore size in this experiment directly, increases in elemental contents do suggest that the chytrid produced larger zoospores. Zoospore size of the used chytrid was shown to vary from 2.84 to $5.36 \mu \mathrm{m}$ under control growth conditions (Supplementary Material), and variation in spore size was also shown in other studies describing shifts in spore size with climatic conditions (Kauserud et al., 2008, 2011). Presumably, larger zoospores facilitate zoospore survival time, since they can contain more lipids and fatty acids that might represent an energy source to fuel zoospore metabolism (Steinhoff et al., 2011). A longer spore survival time may be particularly favorable at lower host densities, and may explain the unaltered chytrid infections in the low $\mathrm{N}: \mathrm{P}$ treatment. Conversely, in the high $\mathrm{N}: \mathrm{P}$ conditions, more zoospores were produced per host biomass but contained less $\mathrm{C}, \mathrm{N}$ and $\mathrm{P}$ per zoospore, suggesting that they were smaller. These findings are supported by earlier observations indicating that the efficiency of spore production by a parasitic dinoflagellate is increased under high N:P conditions, which might result in a higher transmission to new hosts under high host density conditions (Yih and Coats, 2000).

At low N:P supply the chytrid seems to produce a low amount of large zoospores, while at high $\mathrm{N}: \mathrm{P}$ supply it produced a higher amount of small zoospores. The chytrid thus possibly produced smaller spores with a higher production efficiency (Figure 4C), suggesting a trade-off between size and production rate as well as success of infection. In other words, larger spores may survive longer providing the chytrid more time to find a suitable host under low host density conditions, while smaller ones survive less long but due to their high numbers achieve a higher infection transmission in high host density conditions. A trade-off between organism size and growth rate has also been reported for various other organisms, including phytoplankton (Nielsen, 2006) and zooplankton (Stemberger and Gilbert, 1985). Moreover, a tradeoff between zoospore survival time and production rate was observed in another chytrid, the amphibian killing fungus Batrachochytrium dendrobatidis (Woodhams et al., 2008). Thus, changes in host N:P stoichiometry may affect the growth strategy of the parasite, following a more general trade-off between cell size and production rates (Figure 4C). Such changes can have consequences not only for the infection dynamics, but also for higher trophic levels that are provided with either many smaller zoospores, or fewer larger ones.

As expected, intracellular MC content closely followed the relative availability of $\mathrm{N}$, and thus increased with cellular $\mathrm{N}: \mathrm{P}$ ratios (Figure 5). These results are in line with earlier work, showing a strong dependency of MC contents on $\mathrm{N}$ availability (Van de Waal et al., 2009, 2010). In the treatment with high N:P supply and high MC production, however, zoospore production (Figure 4A) and infection rate (Table 1) were highest. Additionally, in the low N:P treatment, MC contents was lowest 

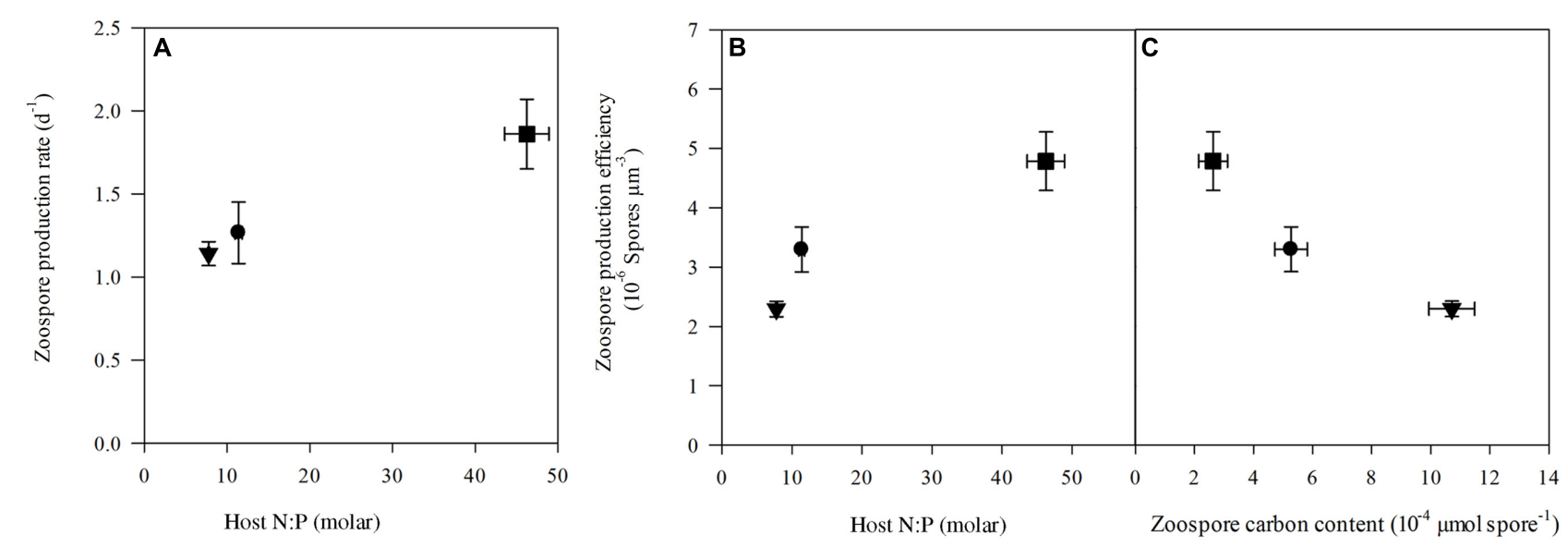

FIGURE 4 | Zoospore production rate (A) and production efficiency (B) plotted against host N:P and zoospore carbon content (C) in the control (circle), low N:P (triangle) and high N:P (square) treatments. Symbols represent mean \pm standard error $(n=4)$.

TABLE 4 | Zoospore production rates and production efficiencies (mean \pm SE).

\begin{tabular}{lcc}
\hline Treatment & Rate $\left(\mathbf{d}^{-\mathbf{1}}\right)$ & $\begin{array}{c}\text { Efficiency }\left(\mathbf{1 0}^{-\mathbf{6}}\right. \\
\left.\text { spores } \boldsymbol{\mu \mathbf { m } ^ { - 3 }}\right)\end{array}$ \\
\hline Low N:P & $1.14 \pm 0.07^{\mathrm{a}}$ & $2.17 \pm 0.04^{\mathrm{a}}$ \\
Control & $1.27 \pm 0.18^{\mathrm{ab}}$ & $3.14 \pm 0.42^{\mathrm{b}}$ \\
High N:P & $1.86 \pm 0.21^{\mathrm{b}}$ & $5.02 \pm 0.53^{\mathrm{c}}$ \\
\hline
\end{tabular}

Superscript letters denote significant differences between nutrient treatments based on One-way ANOVA and post hoc comparison of the means $(\alpha<0.05)$.

while zoospore production and infection rate were not different from the control. So, there was no clear relation between intracellular MC content and chytrid proliferation. Possibly, a considerable fraction of the total MC might be bound to proteins of cyanobacterial cells (Zilliges et al., 2011), which were not included in our extraction processes. Furthermore, Planktothrix may produce other oligopeptides that play a role in parasite defense systems (Sønstebø and Rohrlack, 2011; Rohrlack et al., 2013), which were not analyzed here.

The intracellular MC seemed to be lower in the parasite exposed treatments as compared to the unexposed treatments. This may possibly result from leakage of MC from the cells into the liquid phase (Jones and Orr, 1994). Moreover, chytrid rhizoids that invade the host cells might use enzymes that are able to digest MC. Indeed, fungi were shown to be capable of degrading MC (Jia et al., 2012). In our experiment, however, extracellular MC concentrations nor chytrid MC contents were analyzed. If $\mathrm{MC}$ is released into the water column from cyanobacterial cells, it can have consequences for other organisms present (Carmichael, 1992; Zurawell et al., 2005). For instance, high MC concentrations in the water can accumulate in Daphnia (Chen et al., 2005) and have adverse effects on growth and development of fish (Jacquet et al., 2004). Yet, actual exposure of other organisms to MC in the water may be limited, as MCs can be rapidly biodegraded and detoxified by bacteria and adsorb to plants and sediments (Harada and Tsuji, 1998; Pflugmacher et al., 2001; Kato et al., 2007). Whether MCs can bind to- or

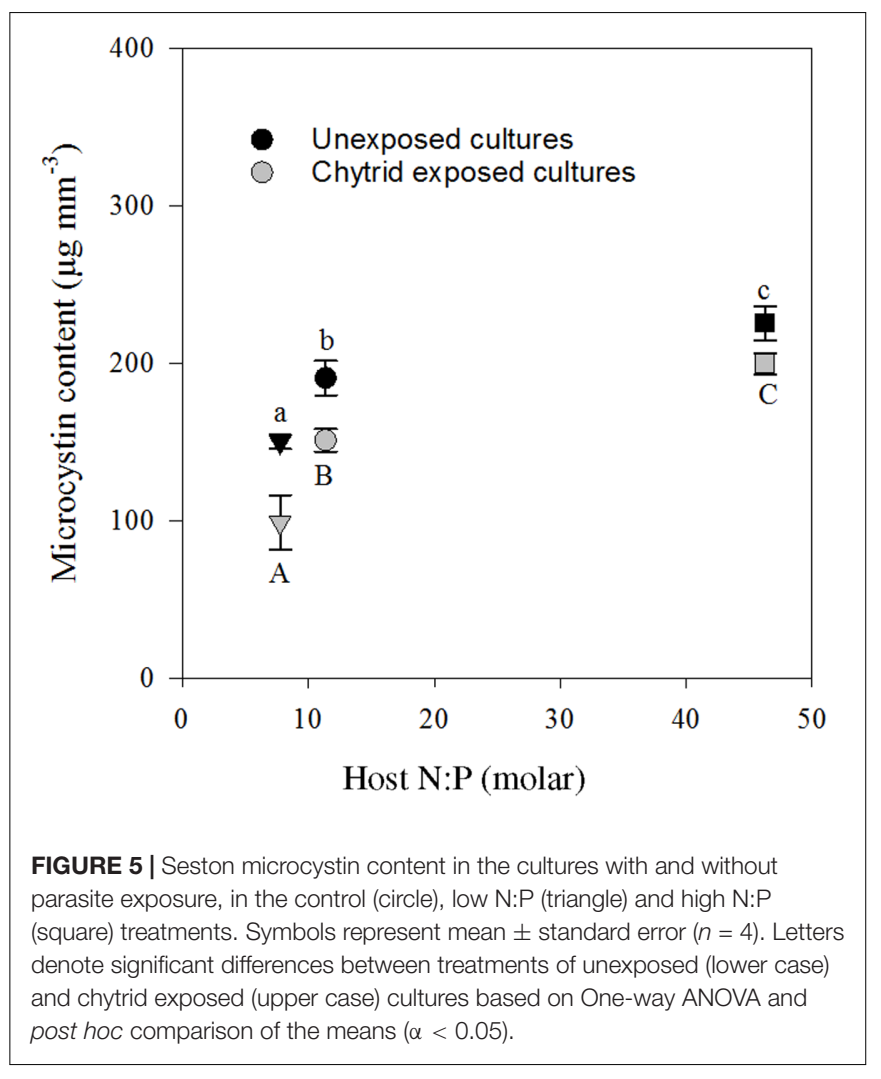

be transported into zoospores is unknown. But, if this would occur, zooplankton might be exposed to MCs via this indirect route, since zoospores can serve as a food source for copepods, cladocerans and possibly rotifers (Kagami et al., 2004, 2007, 2011; Buck et al., 2011; Agha et al., 2016; Frenken et al., 2016).

Our results demonstrate an increase in infection rate with host N:P stoichiometry, thereby showing the opposite to what we hypothesized. Because chytrids seemed relatively more $\mathrm{P}$ rich as compared to their host, we initially predicted that host $\mathrm{P}$ content 
would constrain chytrid growth more than it would constrain the host (Bruning and Ringelberg, 1987; Bruning, 1991). Our results suggest, however, that chytrid proliferation is much more sensitive to the relative availability of $\mathrm{N}$. Specifically, if this increases (i.e., higher host $\mathrm{N}: \mathrm{P}$ ), infection rates increase, while if this decreases (i.e., lower host N:P), infection rates decrease. This is also shown by the lower flexibility of the parasite $\mathrm{N}$ content as compared to $\mathrm{P}$, suggesting that spores are more likely to be constrained under low $\mathrm{N}$ conditions. It remains unclear why infection rates increase under $\mathrm{P}$ limitation and relative high $\mathrm{N}$ contents. Particularly as under these high N:P conditions, MC contents were highest as well. We initially expected that under such conditions, chytrid infections can be inhibited by MCs in its host. The increase in MC content with high N:P conditions, however, was relatively small and may therefore not have been sufficient to inhibit the chytrid infection. Possibly, regulation of other oligopeptides in response to $\mathrm{N}: \mathrm{P}$ supply could have explained the observed responses, and should thus be included in future analyzes. Moreover, other metabolites synthesized by cyanobacteria under high N:P supply may have facilitated chytrid growth and reproduction. Further detailed biochemical analyses of chytrids and their distinct developmental stages would be required to fully understand the stoichiometric interactions with their hosts, and particularly the putative important role of $\mathrm{N}$ in controlling infections.

Our analysis revealed some still poorly understood effects of nutrient availability on the interaction of a host-parasite system. Shifts in nutrient supply ratios not only lead to a shift in host stoichiometry, but also to comparable changes in the parasite. Thereby, we show that elemental stoichiometry of a host can cascade to their parasites. We hypothesize that, in response to changes in nutrient supply, the parasite may exhibit a trade-off between size and zoospore production rate to optimize reproductive success. Therefore, nutrient limitation

\section{REFERENCES}

Agha, R., Saebelfeld, M., Manthey, C., Rohrlack, T., and Wolinska, J. (2016). Chytrid parasitism facilitates trophic transfer between bloom-forming cyanobacteria and zooplankton (Daphnia). Sci. Rep. 6:35039. doi: 10.1038/ srep35039

Armstrong, F. A. J., Stearns, C. R., and Strickland, J. D. H. (1967). The measurement of upwelling and subsequent biological process by means of the Technicon Autoanalyzer ${ }^{\circledR}$ and associated equipment. Deep Sea Res. Oceanogr. Abstr. 14, 381-389. doi: 10.1016/0011-7471(67)90082-4

Barr, D., and Hickman, C. (1967). Chytrids and algae: II. Factors influencing parasitism of Rhizophydium sphaerocarpum on Spirogyra. Can. J. Bot. 45, 431-440. doi: 10.1139/b67-043

Barr, D. J., and Hadland-Hartmann, V. (1978). Zoospore ultrastructure in the genus Rhizophydium (Chytridiales). Can. J. Bot. 56, 2380-2404. doi: 10.1139/b78-290

Barr, D. J. S. (2001). "Chytridiomycota," in Systematics and Evolution: Part A, eds D. J. Mclaughlin, E. G. Mclaughlin, and P. A. Lemke (Berlin: Springer), 93-112. doi: 10.1007/978-3-662-10376-0_5

Beakes, G. W., Canter, H. M., and Jaworski, G. H. (1988). Zoospore ultrastructure of Zygorhizidium affluens and Z. planktonicum, two chytrids parasitizing the diatom Asterionella formosa. Can. J. Bot. 66, 1054-1067. doi: 10.1139/ b88-151

Beakes, G. W., Canter, H. M., and Jaworski, G. H. M. (1993). Sporangium differentiation and zoospore fine-structure of the chytrid Rhizophydium may indirectly affect parasite abundance and stoichiometry. Since chytrids can facilitate growth of zooplankton (Kagami et al., 2007; Agha et al., 2016), changes in parasite production, stoichiometry and cell size may have implications for aquatic food web dynamics.

\section{AUTHOR CONTRIBUTIONS}

TF, JW, and DVdW designed the study. JW and TF performed the experiment. TF, JW, AG, and DVdW analyzed and interpreted the data. TF and DVdW wrote a first draft of the manuscript which was corrected, revised and approved by all authors.

\section{FUNDING}

AG is supported by a NWO-veni grant (016.Veni.171.063).

\section{ACKNOWLEDGMENTS}

We are grateful to Nico Helmsing and Erik Reichman for assistance during the experiment and for analyses of $\mathrm{MC}$ and seston elemental composition. We also thank Suzanne NausWiezer for help and advice with microscopic work and Els Faassen for advice on MC analyses.

\section{SUPPLEMENTARY MATERIAL}

The Supplementary Material for this article can be found online at: http://journal.frontiersin.org/article/10.3389/fmicb. 2017.01015/full\#supplementary-material

planktonicum, a fungal parasite of Asterionella formosa. Mycol. Res. 97, 1059-1074. doi: 10.1016/S0953-7562(09)80507-8

Bracken, M. E. S., Hillebrand, H., Borer, E. T., Seabloom, E. W., Cebrian, J., Cleland, E. E., et al. (2014). Signatures of nutrient limitation and co-limitation: responses of autotroph internal nutrient concentrations to nitrogen and phosphorus additions. Oikos 124, 113-121. doi: 10.1111/oik.01215

Bruning, K. (1991). Effects of phosphorus limitation on the epidemiology of a chytrid phytoplankton parasite. Freshw. Biol. 25, 409-417. doi: 10.1111/j.13652427.1991.tb01385.x

Bruning, K., and Ringelberg, J. (1987). The influence of phosphorus limitation of the diatom Asterionella formosa on the zoospore production of its fungal parasite Rhizophydium Planktonicum. Hydrobiol. Bull. 21, 49-54. doi: 10.1007/ BF02255454

Buck, J. C., Truong, L., and Blaustein, A. R. (2011). Predation by zooplankton on Batrachochytrium dendrobatidis: biological control of the deadly amphibian chytrid fungus? Biodivers. Conserv. 20, 3549-3553. doi: 10.1007/s10531-0110147-4

Canter, H. M., and Lund, J. (1951). Studies on plankton parasites III. Examples of the interaction between parasitism and other factors determining the growth of diatoms. Ann. Bot. 15, 359-371. doi: 10.1093/oxfordjournals.aob.a083287

Carmichael, W. (1992). Cyanobacteria secondary metabolites-the cyanotoxins. J. Appl. Bacteriol. 72, 445-459. doi: 10.1111/j.1365-2672.1992.tb01858.x

Carpenter, S. R., Kitchell, J. F., Cottingham, K. L., Schindler, D. E., Christense, D. L., Post, D. M., et al. (1996). Chlorophyll variability, nutrient input, 
and grazing: evidence from whole- lake experiments. Ecology 77, 725-735. doi: $10.2307 / 2265497$

Chen, W., Song, L., Ou, D., and Gan, N. (2005). Chronic toxicity and responses of several important enzymes in Daphnia magna on exposure to sublethal microcystin-LR. Environ. Toxicol. 20, 323-330. doi: 10.1002/tox.20108

Danger, M., and Chauvet, E. (2013). Elemental composition and degree of homeostasis of fungi: Are aquatic hyphomycetes more like metazoans, bacteria or plants? Fungal Ecol. 6, 453-457. doi: 10.1016/j.funeco.2013.05.007

Danger, M., Gessner, M. O., and Bärlocher, F. (2015). Ecological stoichiometry of aquatic fungi: current knowledge and perspectives. Fungal Ecol. 19, 100-111. doi: 10.1016/j.funeco.2015.09.004

Donaldson, S. P., and Deacon, J. W. (1993). Effects of amino acids and sugars on zoospore taxis, encystment and cyst germination in Pythium aphanidermatum (Edson) Fitzp., P. catenulatum Matthews and P. dissotocum Drechs. New Phytol. 123, 289-295. doi: 10.1111/j.1469-8137.1993.tb03738.x

Eaton, A. D. (2005). Standard Methods for the Examination of Water and Wastewater. Washington, DC: APHA-AWWA-WEF,

Elser, J. J., Bracken, M. E. S., Cleland, E. E., Gruner, D. S., Harpole, W. S., Hillebrand, H., et al. (2007). Global analysis of nitrogen and phosphorus limitation of primary producers in freshwater, marine and terrestrial ecosystems. Ecol. Lett. 10, 1135-1142. doi: 10.1111/j.1461-0248.2007.01113.x

Elser, J. J., Dobberfuhl, D. R., Mackay, N. A., and Schampel, J. H. (1996). Organism size, life history, and N: P stoichiometry toward a unified view of cellular and ecosystem processes. Bioscience 46, 674-684. doi: 10.2307/1312897

Faassen, E., and Lürling, M. (2013). Occurrence of the microcystins MC-LW and MC-LF in Dutch surface waters and their contribution to total microcystin toxicity. Mar. Drugs 11, 2643-2654. doi: 10.3390/md11072643

Frenken, T., Velthuis, M., De Senerpont Domis, L. N., Stephan, S., Aben, R., Kosten, S., et al. (2016). Warming accelerates termination of a phytoplankton spring bloom by fungal parasites. Glob. Change Biol. 22, 299-309. doi: 10.1111/ gcb. 13095

Gerphagnon, M., Macarthur, D. J., Latour, D., Gachon, C. M. M., Van Ogtrop, F., Gleason, F. H., et al. (2015). Microbial players involved in the decline of filamentous and colonial cyanobacterial blooms with a focus on fungal parasitism. Environ. Microbiol. 17, 2573-2587. doi: 10.1111/1462-2920.12860

Guillard, R. R. L., and Lorenzen, C. J. (1972). Yellow-green algae with chlorophyllide C. J. Phycol. 8, 10-14.

Harada, K.-I., and Tsuji, K. (1998). Persistence and decomposition of hepatotoxic microcystins produced by cyanobacteria in natural environment. J. Toxicol. Toxin Rev. 17, 385-403. doi: 10.3109/15569549809040400

Hessen, D. O., Elser, J. J., Sterner, R. W., and Urabe, J. (2013). Ecological stoichiometry: an elementary approach using basic principles. Limnol. Oceanogr. 58, 2219-2236. doi: 10.4319/lo.2013.58.6.2219

Jacquet, C., Thermes, V., Luze, A. D., Puiseux-Dao, S., Bernard, C., Joly, J.-S., et al. (2004). Effects of microcystin-LR on development of medaka fish embryos (Oryzias latipes). Toxicon 43, 141-147. doi: 10.1016/j.toxicon.2003.11.010

Jia, Y., Du, J., Song, F., Zhao, G., and Tian, X. (2012). A fungus capable of degrading microcystin-LR in the algal culture of Microcystis aeruginosa PCC7806. Appl. Biochem. Biotechnol. 166, 987-996. doi: 10.1007/s12010-0119486-6

Jones, G. J., and Orr, P. T. (1994). Release and degradation of microcystin following algicide treatment of a Microcystis aeruginosa bloom in a recreational lake, as determined by HPLC and protein phosphatase inhibition assay. Water Res. 28, 871-876. doi: 10.1016/0043-1354(94)90093-0

Kagami, M., Helmsing, N., and Van Donk, E. (2011). Parasitic chytrids could promote copepod survival by mediating material transfer from inedible diatoms. Hydrobiologia 659, 49-54. doi: 10.1007/s10750-010-0274-z

Kagami, M., Motoki, Y., Masclaux, H., and Bec, A. (2017). Carbon and nutrients of indigestible pollen are transferred to zooplankton by chytrid fungi. Freshw. Biol. 62, 954-964. doi: 10.1111/fwb.12916

Kagami, M., Van Donk, E., De Bruin, A., Rijkeboer, M., and Ibelings, B. W. (2004). Daphnia can protect diatoms from fungal parasitism. Limnol. Oceanogr. 49, 680-685. doi: 10.4319/lo.2004.49.3.0680

Kagami, M., Von Elert, E., Ibelings, B. W., De Bruin, A., and Van Donk, E. (2007). The parasitic chytrid, Zygorhizidium, facilitates the growth of the cladoceran zooplankter, Daphnia, in cultures of the inedible alga, Asterionella. Proc. R. Soc. B Biol. Sci. 274, 1561-1566. doi: 10.1098/rspb.2007.0425
Kato, H., Imanishi, S. Y., Tsuji, K., and Harada, K.-I. (2007). Microbial degradation of cyanobacterial cyclic peptides. Water Res. 41, 1754-1762. doi: 10.1016/j. watres.2007.01.003

Kauserud, H., Colman, J. E., and Ryvarden, L. (2008). Relationship between basidiospore size, shape and life history characteristics: a comparison of polypores. Fungal Ecol. 1, 19-23. doi: 10.1016/j.funeco.2007.12.001

Kauserud, H., Heegaard, E., Halvorsen, R., Boddy, L., Høiland, K., and Stenseth, N. C. (2011). Mushroom's spore size and time of fruiting are strongly related: Is moisture important? Biol. Lett. 7, 273-276. doi: 10.1098/rsbl.2010.0820

Moss, A. S., Reddy, N. S., Dortaj, I. M., and San Francisco, M. J. (2008). Chemotaxis of the amphibian pathogen Batrachochytrium dendrobatidis and its response to a variety of attractants. Mycologia 100, 1-5. doi: 10.1080/15572536.2008. 11832493

Muehlstein, L. K., Amon, J. P., and Leffler, D. L. (1988). Chemotaxis in the marine fungus Rhizophydium littoreum. Appl. Environ. Microbiol. 54, 1668-1672.

Nielsen, S. L. (2006). Size-dependent growth rates in eukaryotic and prokaryotic algae exemplified by green algae and cyanobacteria: comparisons between unicells and colonial growth forms. J. Plankton Res. 28, 489-498. doi: 10.1093/ plankt/fbi134

Paerl, H. W., Fulton, R. S., Moisander, P. H., and Dyble, J. (2001). Harmful freshwater algal blooms, with an emphasis on cyanobacteria. ScientificWorldJournal 1, 76-113. doi: 10.1100/tsw.2001.16

Paerl, H. W., Hall, N. S., and Calandrino, E. S. (2011). Controlling harmful cyanobacterial blooms in a world experiencing anthropogenic and climaticinduced change. Sci. Total Environ. 409, 1739-1745. doi: 10.1016/j.scitotenv. 2011.02.001

Persson, J., Fink, P., Goto, A., Hood, J. M., Jonas, J., and Kato, S. (2010). To be or not to be what you eat: regulation of stoichiometric homeostasis among autotrophs and heterotrophs. Oikos 119, 741-751. doi: 10.1111/j.1600-0706.2009.18545.x

Pflugmacher, S., Wiegand, C., Beattie, K. A., Krause, E., Steinberg, C. E. W., and Codd, G. A. (2001). Uptake, effects, and metabolism of cyanobacterial toxins in the emergent reed plant Phragmites australis (Cav.) Trin. ex steud. Environ. Toxicol. Chem. 20, 846-852. doi: 10.1002/etc.5620200421

Reynolds, C. (1973). The seasonal periodicity of planktonic diatoms in a shallow eutrophic lake. Freshw. Biol. 3, 89-110. doi: 10.1111/j.1365-2427.1973. tb00065.x

Rohrlack, T., Christiansen, G., and Kurmayer, R. (2013). Putative antiparasite defensive system involving ribosomal and nonribosomal oligopeptides in cyanobacteria of the genus Planktothrix. Appl. Environ. Microbiol. 79, 2642-2647. doi: 10.1128/AEM.03499-12

Schindler, D. W., and Fee, E. J. (1974). Experimental lakes area: whole-lake experiments in eutrophication. J. Fish. Res. Board Can. 31, 937-953. doi: 10. $1139 / \mathrm{f} 74-110$

Sidak, Z. (1967). Rectangular confidence regions for the means of multivariate normal distributions. J. Am. Stat. Assoc. 62, 626-633. doi: 10.2307/2283989

Sime-Ngando, T. (2012). Phytoplankton chytridiomycosis: fungal parasites of phytoplankton and their imprints on the food web dynamics. Front. Microbiol. 3:361. doi: $10.3389 /$ fmicb. 2012.00361

Smith, V. (2007). Host resource supplies influence the dynamics and outcome of infectious disease. Integr. Comp. Biol. 47, 310-316. doi: 10.1093/icb/icm006

Smith, V. H. (2003). Eutrophication of freshwater and coastal marine ecosystems a global problem. Environ. Sci. Pollut. Res. 10, 126-139. doi: 10.1065/espr2002. 12.142

Smith, V. H., Joye, S. B., and Howarth, R. W. (2006). Eutrophication of freshwater and marine ecosystems. Limnol. Oceanogr. 51, 351-355. doi: 10.4319/lo.2006. 51.1_part_2.0351

Smith, V. H., and Schindler, D. W. (2009). Eutrophication science: Where do we go from here? Trends Ecol. Evol. 24, 201-207. doi: 10.1016/j.tree.2008.11.009

Sønstebø, J. H., and Rohrlack, T. (2011). Possible implications of chytrid parasitism for population subdivision in freshwater cyanobacteria of the genus Planktothrix. Appl. Environ. Microbiol. 77, 1344-1351. doi: 10.1128/AEM. 02153-10

Sparrow, F. K. (1960). Aquatic Phycomycetes. Ann Arbor, MI: University of Michigan Press. doi: 10.5962/bhl.title.5685

Sparrow, F. K. (1968). "Ecology of freshwater fungi," in The Fungi. An Advanced Treatise: The Fungal Population, eds G. Ainsworth and A. Sussman (New York, NY: Academia Press), 41-93. 
Steinhoff, F. S., Graeve, M., Wiencke, C., Wulff, A., and Bischof, K. (2011). Lipid content and fatty acid consumption in zoospores/developing gametophytes of Saccharina latissima (Laminariales, Phaeophyceae) as potential precursors for secondary metabolites as phlorotannins. Polar Biol. 34, 1011-1018. doi: 10.1007/s00300-011-0960-y

Stemberger, R. S., and Gilbert, J. J. (1985). Body size, food concentration, and population growth in planktonic rotifers. Ecology 66, 1151-1159. doi: 10.2307/ 1939167

Sterner, R. W., Anagnostou, E., Brovold, S., Bullerjahn, G. S., Finlay, J. C., Kumar, S., et al. (2007). Increasing stoichiometric imbalance in North America's largest lake: nitrification in lake superior. Geophys. Res. Lett. 34:L10406. doi: 10.1029/2006GL028861

Sterner, R. W., and Elser, J. J. (2002). Ecological Stoichiometry: The Biology of Elements from Molecules to the Biosphere. Princeton, NJ: Princeton University Press.

Van de Waal, D. B., Ferreruela, G., Tonk, L., Van Donk, E., Huisman, J., Visser, P. M., et al. (2010). Pulsed nitrogen supply induces dynamic changes in the amino acid composition and microcystin production of the harmful cyanobacterium Planktothrix agardhii. FEMS Microbiol. Ecol. 74, 430-438. doi: 10.1111/j.1574-6941.2010.00958.x

Van de Waal, D. B., Smith, V. H., Declerck, S. A. J., Stam, E. C. M., and Elser, J. J. (2014). Stoichiometric regulation of phytoplankton toxins. Ecol. Lett. 17, 736-742. doi: 10.1111/ele.12280

Van de Waal, D. B., Verspagen, J. M., Lürling, M., Van Donk, E., Visser, P. M., and Huisman, J. (2009). The ecological stoichiometry of toxins produced by harmful cyanobacteria: an experimental test of the carbon-nutrient balance hypothesis. Ecol. Lett. 12, 1326-1335. doi: 10.1111/j.1461-0248.2009.01383.x

Van Donk, E. (1984). Factors influencing phytoplankton growth and succession in Lake Maarsseveen I. Hydrobiol. Bull. 18, 69-71. doi: 10.1007/BF02 256678

Van Donk, E. (1989). "The role of fungal parasites in phytoplankton succession," in Plankton Ecology, ed. U. Sommer (Berlin: Springer), 171-194. doi: 10.1007/ 978-3-642-74890-5_5
Van Donk, E., and Ringelberg, J. (1983). The effect of fungal parasitism on the succession of diatoms in Lake Maarsseveen I (The Netherlands). Freshw. Biol. 13, 241-251. doi: 10.1111/j.1365-2427.1983.tb00674.x

Welker, M., and Von Döhren, H. (2006). Cyanobacterial peptides - nature's own combinatorial biosynthesis. FEMS Microbiol. Rev. 30, 530-563. doi: 10.1111/j. 1574-6976.2006.00022.x

Woodhams, D. C., Alford, R. A., Briggs, C. J., Johnson, M., and Rollins-Smith, L. A. (2008). Life-history trade-offs influence disease in changing climates: strategies of an amphibian pathogen. Ecology 89, 1627-1639. doi: 10.1890/06-1842.1

Yih, W., and Coats, D. W. (2000). Infection of Gymnodinium sanguineum by the dinoflagellate Amoebophrya sp.: effect of nutrient environment on parasite generation time, reproduction, and infectivity. J. Eukaryot. Microbiol. 47, 504510. doi: 10.1111/j.1550-7408.2000.tb00082.x

Zilliges, Y., Kehr, J.-C., Meissner, S., Ishida, K., Mikkat, S., Hagemann, M., et al. (2011). The cyanobacterial hepatotoxin microcystin binds to proteins and increases the fitness of Microcystis under oxidative stress conditions. PLoS ONE 6:e17615. doi: 10.1371/journal.pone.0017615

Zurawell, R. W., Chen, H., Burke, J. M., and Prepas, E. E. (2005). Hepatotoxic cyanobacteria: a review of the biological importance of microcystins in freshwater environments. J. Toxicol. Environ. Health B Crit. Rev. 8, 1-37. doi: 10.1080/10937400590889412

Conflict of Interest Statement: The authors declare that the research was conducted in the absence of any commercial or financial relationships that could be construed as a potential conflict of interest.

Copyright (c) 2017 Frenken, Wierenga, Gsell, van Donk, Rohrlack and Van de Waal. This is an open-access article distributed under the terms of the Creative Commons Attribution License (CC BY). The use, distribution or reproduction in other forums is permitted, provided the original author(s) or licensor are credited and that the original publication in this journal is cited, in accordance with accepted academic practice. No use, distribution or reproduction is permitted which does not comply with these terms. 